\title{
Erratum to: What is the Diagnostic Accuracy of Aspirations Performed on Hips With Antibiotic Cement Spacers?
}

\author{
Jared M. Newman MD, Jaiben George MBBS, Alison K. Klika MS, \\ Stephen F. Hatem MD, Wael K. Barsoum MD, W. Trevor North MD, \\ Carlos A. Higuera MD
}

Published online: 12 April 2017

(C) The Association of Bone and Joint Surgeons( 2017

\section{Erratum to: Clin Orthop Relat Res \\ DOI: $10.1007 / \mathrm{s} 11999-016-5093-8$}

In the published study, "What is the Diagnostic Accuracy of Aspirations Performed on Hips With Antibiotic Cement
Spacers?" a coauthor's name is listed incorrectly on pubmed.gov. The coauthor's name, W. Trevor North, should be listed on the PubMed website as "North WT" not "Trevor North W."

The publisher apologizes for the error.

The online version of the original article can be found under doi:10. 1007/s11999-016-5093-8.

J. M. Newman, J. George, A. K. Klika ( $₫)$, W. K. Barsoum,

W. T. North, C. A. Higuera

Department of Orthopaedic Surgery, Cleveland Clinic, A41,

9500 Euclid Avenue, Cleveland, OH 44195, USA

e-mail: klikaa@ccf.org

S. F. Hatem

Department of Radiology, Cleveland Clinic, Cleveland, OH,

USA 